\title{
Current Research and Developments for Civil Engineering in Germany
}

\author{
Maximilian Schöberl*, Zhen Cai, Anne Fischer and Stephan Kessler \\ Chair of Materials Handling, Material Flow, Logistics, Technical University of Munich, Germany
}

*Corresponding author: Maximilian Schöberl, Boltzmannstraße 15, 85748 Garching bei München, Germany.

Received Date: January 10, 2019

Published Date: January 28, 2020

\section{Introduction}

Productivity of the construction industry stagnated in the recent decades [1] while other industries' productivities were on the rise. Multiple differentiating factors between the construction and other industries are held accountable for this development. Fragmentation, individuality, variability and variance to name a few macroscopic examples. In order to foster research and development on the productivity of the construction industry, these macroscopic factors are broken down to microscopic, practical examples from the German construction industry in the first part of this article. The second part contains an overview of the works of a joint research project on the issue and the last part further examines the research agenda on the digitalization of construction processes.

\section{Current State in Germany and Research Opportunities}

About $97 \%$ of the German construction companies are small or medium sized companies ( $<50$ employees)[2]. Along with this high number of contractors, a high percentage of subcontractors (30-75\% of the project volume [3]) per jobsite leads to a high degree of fragmentation, limiting continuity and consistency in all aspects. Another major point in the construction industry is the individual character of the projects. In Germany, the major mode of construction is project-based [4]. Thereby, a lot of planning and development effort is individually adapted to the project and not reused in other projects. Leading to an avoidable amount of rework in each project. While the stationary industry produces under constant conditions, the construction site is under the influence of variable conditions, like the weather and varying site locations. In Germany, temperatures can for example range from $-20^{\circ} \mathrm{C}$ to above $40^{\circ} \mathrm{C}$. Therefore, major requirements on productivity enhancers in the construction industry are robustness and adaptability. Finally, companies in stationary industries fall under a high degree of functional specialization [5]. In the German construction industry, most companies are rather specialized on a certain region [6] than on a function, like earthworks or civil engineering. The inevitable variance in project kinds limits the optimization and thereby productivity increase in the individual functions. In order to act on the shortcomings and resulting research opportunities, a group of German construction, engineering and research organizations formed the research project: Building 4.0-Digitalization of the Construction Site, funded by the German Federal Ministry of Education and Research.

\section{Research Project: Building 4.0-Digitalization of the} Construction Site

The research project has threefold objectives. First, the construction machinery is to be connected and automated through the development of intelligent sensors and assistance systems in order to increase the individual machines' productivity. Second, a suitable, digital infrastructure is to be implemented for the construction site. Major topics in this field are decentralized intelligence, cloud solutions and reliable as well as secure data exchange in 5G networks. Third, the construction processes are to be digitized and digitalized. Therefore, necessary data is to be defined, collected through tracking and tracing as well as telematics solutions and used in real-time process simulations, digital twins of the construction site and it's machinery. In the next section, the third aspect is further elaborated and set into context with the factors hindering a productivity increase in construction.

\section{Digital Construction Processes}

Digitalizing and increasing the productivity of construction processes starts with digitizing. Therefore, the currently manual and analog workflows have to be represented in the digital environment. All material flows, equipment movements and equipment stocks on the construction site are to be recorded. This 
should be done via Tracking and Tracing (TaT) of the objects. Here the value of the objects is clustered, i.e. more complex techniques can be used for expensive objects. Cheap items must be traceable with low-cost technology. From barcodes to the Internet of Things (IoT), all possible techniques are considered and evaluated. Significant examples enduring the variable conditions on site are implemented in demonstrators. As well as equipment and material, data generated by the machines has to be standardized and effectively analyzed. The current standard for construction machinery telematics data is the ISO 15143-3, which will be revised in 2020. In order to enhance the revised standard from earthmoving to more construction machinery and to add process and quality data to the current status data, the German Machinery and Plant Manufacturing Association (VDMA) established the spinoff Machines in Construction (MiC) 4.0 [7]. The clusters of the spinoff are well-staffed with major original equipment manufacturers, construction companies and suppliers. First results will be achieved in early 2020. The data generated through the depicted channels have to be further processed in order to optimize the productivity of construction processes. A very effective way to reduce project lengths is the macro and micro simulation of project plans and workflows. Both approaches, the detailed, and the higher-level process simulation, will be explored in the course of the joint research project. The main focus will lie on the integration of real-time machine data to give recommendations for action. Additionally, the results from the detailed process simulation of the machine operations will be integrated into the higher-level process simulation of the construction works to enable a consistent and continuous view on a fragmented process environment.

Combined with the process simulation, the geometrical and informational model form the digital twin of the construction site. Currently the standard geometrical models widely used in construction are BIM models in the *ifc-format. In the course of the project, they will be extended to depict construction steps, equipment, and machinery with their natural characteristics and behavior e.g. kinematics. In the background of the geometrical model will be an informational model, mapping construction tasks to machine functions and parameters, increasing the operational effectivity and reuse of reoccurring work-breakdown structures. The informational model will also facilitate the distribution of tasks through a construction site management system. The system will be coupled to an operator assistance system, visualizing relevant real-time and planning data. Therefore, AR glasses are worn by the operator, which are connected to different databases. A feasibility study on this system has already been carried out and won the bauma innovation award 2019 [8]. The next steps in the project will be the realization of a broad study on the state and potentials of digitalization in the construction industry. This study and other early results will be published in early 2020 .

\section{Acknowledgement}

The authors thank the German Federal Ministry of Education and Research for funding this research project.

\section{Conflict of Interests}

There is no conflict of interests.

\section{References}

1. Organisation for Economic Co-operation and Development (2019) Productivity and ULC by main economic activity (ISIC Rev4).

2. Kraus P (2019) Structure-The German construction industry.

3. Tomic A (2014) eBook: Construction time and time-dependent costs: in award, contract and addendum - causes of changes and their consequences.

4. Klaubert C (2011) Entwicklung eines RFID-basierten Informations-und Kommunikationssystems für die Baulogistik, Munich.

5. Zijm H, Klumpp M (2016) Future Logistics: What to Expect, How to Adapt. In: Freitag M, Kotzab H, Pannek J (Eds.) Dynamics in Logistics: Proceedings of the $5^{\text {th }}$ International Conference LDIC p.365-381, 9783319451176

6. Bundesinstitut für Bau-, Stadt- und Raumforschung im Bundesamt für Bauwesen und Raumordnung (2012) Bauwirtschaft in den Regionen.

7. Verein Deutscher Maschinen- und Anlagenabuer e.V. (VDMA) (2019) Founding meeting at bauma: New working group Machines in Construction 4.0 .

8. Chair of Materials Handling, Material Flow, Logistics (2019) Winner of the bauma Innovation Award 2019 in the category Research \& Science. 